\title{
FORTUITOUS FACTORS AFFECTING THE THEUCOCYTE COUNT IN BLOOD FROM
THE EAR
}

BY

\author{
H. C. LUCEY \\ From the Pathological Department, Haymeads Hospital, Bishop's Stortford
}

(RECEIVED FOR PUBLICATION JANUARY 13, 1950)

The technique of a leucocyte count comprises not only accurate counting of cells but also taking a reliable sample of blood so that the cell picture reflects that found in the general circulation. It is usual for textbooks to enumerate the sites for skin puncture, and they may mention one or more of the following points: (1) wiping away the first drop of blood, (2) use of alcohol or ether for cleaning the skin, (3) rubbing to cause hyperaemia, and (4) avoidance of squeezing.

\section{Choice of Blood Drop}

It is frequently advised that the first drop or two of blood should be wiped away and a subsequent one used, but the reason for doing this, namely, skin contamination of the first few drops, is only mentioned by Gulland and Goodall (1925). In practice no special care need be taken against skin contamination. Theoretically a few squamous cells or extraneous matter might conceivably contaminate the drop, but do not affect the blood count.

Under certain circumstances, however, a very real reason exists for not using the first drop of blood from the ear which, if not realized, may lead to serious errors in the leucocyte count. Lucey (1921) pointed out the importance of seemingly unimportant differences in technique on the percentage monocyte count. Two people taking a blood film from an ear of the same man, both films being counted by one individual, could produce very different results in the number of monocytes present, variations from 5 to $40 \%$ being encountered. The first drop from the ear usually showed a high monocyte count, whereas subsequent drops gave normal counts. These films were made by pricking the skin without subjecting it to any preliminary treatment such as cleaning with alcohol or ether, or rubbing or massaging it to cause hyperaemia.

\section{Site of Puncture}

The two sites commonly used in adults are the ear and finger. Many haematologists prefer the ear, the advantages claimed for it being that it yields successive drops of blood more readily, is out of sight of the patient, and is less sensitive.

Table I shows a series of observations on healthy men and malarial patients comparing the monocyte counts in the first and third drops from a single puncture from each of the four places usually chosen for obtaining blood drops: the lobule of 
TABLE I

Analysis of Monocyte Count in Normals and Malaria Patients

\begin{tabular}{|c|c|c|c|c|c|c|c|c|c|}
\hline \multirow{3}{*}{ Case } & \multicolumn{9}{|c|}{ Percentage of Monocytes } \\
\hline & \multicolumn{2}{|c|}{$\begin{array}{l}\text { Lobule of } \\
\text { Right Ear }\end{array}$} & \multicolumn{2}{|c|}{$\begin{array}{l}\text { Border of } \\
\text { Right Ear }\end{array}$} & \multicolumn{2}{|c|}{$\begin{array}{c}\text { Base of } \\
\text { Nail }\end{array}$} & \multicolumn{2}{|c|}{$\begin{array}{l}\text { Pulp of } \\
\text { Finger }\end{array}$} & \multirow[t]{2}{*}{ Vein } \\
\hline & Drop 1 & Drop 3| & Drop 1 & Drop 3 & Drop 1 & Drop 3 & Drop 1 & Drop 3 & \\
\hline 1. Normal & 24 & 5 & 20 & 6.5 & 7 & 7 & 5.2 & 6 & 5.5 \\
\hline 2. Normal & 35 & 7 & 41 & 8.5 & 6.5 & 8 & 6 & 5.5 & 7 \\
\hline 3. Normal & 8 & 8 & 27 & 6.5 & 7 & 7.2 & 5.5 & 8.2 & 6.5 \\
\hline 4. Normal & 22 & 11 & 10 & 10 & -9.2 & 12 & 11 & 9.5 & 9.5 \\
\hline 5. Normal & 9.5 & 7 & 6.5 & 7.5 & 6 & 6 & 8 & 5.2 & 6 \\
\hline 6. Normal & 10 & 9.2 & 16 & 8.5 & 12 & 10 & 9.5 & 11 & 8 \\
\hline $\begin{array}{l}\text { 7. Malaria. Plasmodium vivax. } \\
\text { Heavy infection. Late amoe- } \\
\text { boid forms and schizonts ... }\end{array}$ & 28 & 20 & 37 & 21 & 20 & 20 & 22 & 21 & 19 \\
\hline $\begin{array}{l}\text { 8. Malaria. Plasmodium vivax. } \\
\text { Scanty infection. Very few } \\
\text { early amoeboid forms }\end{array}$ & 32 & 9 & 31 & 8.5 & 9.5 & 8 & 7.5 & 8.5 & 8.5 \\
\hline 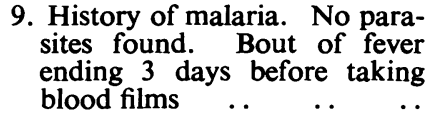 & 19 & 17 & 33 & 15 & 17 & 19 & 16 & 17 & - \\
\hline
\end{tabular}

ear, border of ear, base of finger-nail, and pulp of finger. Blood was also taken from a vein. The first drops from the ear were kept small, and care was taken not to stimulate the local circulation before the prick was made. The ear was supported on the finger rather than grasped firmly, and rubbing the skin with alcohol or ether or massaging the part were avoided. Four hundred cells were counted in each film.

\section{Results}

Our analysis shows that in blood taken from the ear of normals the monocyte count may vary in the first drop taken from different parts, lobule or border, of the same ear. It may be normal in one and raised in the other (Cases 3, 4, and 6). There may be no monocyte increase in the first drop from either lobule or border (Case 5). If the monocyte count is raised, this is found in the first drop but not in the third.

Whether the blood is taken from the base of the nail or pulp of the finger the monocyte count is not raised in either the first or third drops. The counts correspond not only with each other but with counts from the third drops taken from the ear.

The count in venous blood corresponds with any drops from the finger and with the third drops from the ear.

True and False Blood Pictures.-These results indicate that monocyte counts from the vein, the finger, and the third drops from the ear represent true pictures, 
whereas those from the first drop from the ear, when raised above normal, are false pictures.

Two cases with malaria (Cases 7 and 9) showed a true monocyte increase from all sites and an added higher count from the first drops from the ear, and one patient (Case 8) showed a normal count except from the first drops from the ear.

Blood was taken from the big toe, heel, leg, forearm, and tip of the nose. In none of these sites was a difference found in the monocyte count in the first and third drops.

\section{Explanation of the Phenomenon}

The ear in man is exposed to changes of temperature and, being an immobile appendage, its circulation is not aided by muscular contraction. In this second respect it is, as an external organ, unique ; for long periods it may not be subjected to warmth, pressure, or any speeding-up of its circulation following an increase in the rate of the general circulation through exercise. In these circumstances its capillary circulation slows down, and the monocytes then tend to cling to and become concentrated along the capillary walls. This concentration, when tapped by puncture, appears in the first drop of blood, and exceptionally, if the first drop taken is a small one, is also present in the second drop but not in the third drop, which represents a refill from the arterioles and is a representative sample of blood in the general circulation. Experiments have shown that when the circulation in the ear is rendered brisk by rubbing, massaging, or flicking it, or by applying heat in the form of a rubber hot-water bottle, the cell concentration is washed into the general circulation and the first drop then becomes a reliable sample of blood. The mere act of grasping the lobule firmly, and expressing a drop or two of blood, may sufficiently stimulate the circulation at this spot so that when a second puncture is made in the immediate locality the monocyte count in the first drop from the second puncture is low compared with the count in the first drop from the first puncture. Exercise, such as bending down several times to touch the toes, was found to disperse the cells.

Effect of External Temperature and Body Posture.-All these observations were made when the air temperature was moderate or cool, and on men who were up and about. When, however, differential counts were made on blood from the ears of outdoor workers during a spell of hot summer weather no concentration of monocytes in the first drop was observed, nor was it found in the winter months among men working in warm rooms.

Patients who are in bed do not show this concentration as the recumbent position, warmth, and occasional pressure of the pillow on the ears all tend to keep the local circulation brisk. It was, however, observed in one bed patient who had been sitting up for several hours near an open window.

\section{Total and Absolute Leucocyte Counts}

Numerous counts were made to determine to what extent when the ear circulation was sluggish, as indicated by a monocyte concentration in the first drop, the differential percentage, total leucocyte, and differential absolute counts were affected.

To bring out clearly any excess of leucocytes in the first over the third drop it was desirable that this first drop should be kept as small as possible because a monocyte concentration tails off as the drop enlarges. Punctures were therefore made which yielded a drop of blood just sufficient to fill a "Thoma" white-cell pipette 
TABLE II

\begin{tabular}{|c|c|c|c|c|c|c|c|c|c|c|c|}
\hline & \multirow[b]{2}{*}{ Case } & \multirow[b]{2}{*}{$\begin{array}{c}\text { No. } \\
\text { of } \\
\text { Drop }\end{array}$} & \multicolumn{4}{|c|}{ Differential Percentage Counts } & \multirow[b]{2}{*}{$\begin{array}{c}\text { Total } \\
\text { Leuco- } \\
\text { cytes } \\
\text { Norma } \\
(5,000- \\
10,000 \\
\text { per } \\
\text { c. } \mathrm{mm} .)\end{array}$} & \multicolumn{4}{|c|}{ Differential Absolute Counts } \\
\hline & & & $\begin{array}{c}\text { Mono- } \\
\text { cytes } \\
\text { Normal } \\
(2-12 \%)\end{array}$ & $\begin{array}{c}\text { Neutro- } \\
\text { phils } \\
\text { Normal } \\
(50- \\
70 \%)\end{array}$ & $\begin{array}{l}\text { Lympho- } \\
\text { cytes } \\
\text { Normal } \\
(20- \\
35 \%)\end{array}$ & $\begin{array}{l}\text { Eosino- } \\
\text { phils } \\
\text { Normal } \\
(1-4 \%)\end{array}$ & & $\begin{array}{c}\text { Mono- } \\
\text { cytes } \\
\text { Normal } \\
(200- \\
1,000 \\
\text { per } \\
\text { c.mm. })\end{array}$ & \begin{tabular}{|} 
Neutro- \\
phils \\
Normal \\
$(3,000-$ \\
6,500 \\
per \\
c. $\mathrm{mm})$.
\end{tabular} & \begin{tabular}{|} 
Lympho- \\
cytes \\
Normal \\
$(1,250-$ \\
3,250 \\
per \\
c. mm. $)$
\end{tabular} & \begin{tabular}{|c} 
Eosino- \\
phils \\
Normal \\
$(50-$ \\
400 \\
per \\
c. mm. $)$
\end{tabular} \\
\hline \multirow{6}{*}{ 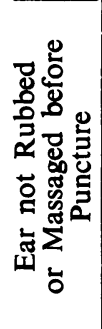 } & \multirow{2}{*}{1} & First & 29.2 & 37.5 & 32.2 & 1.0 & 8,875 & 2,591 & 3,328 & 2,857 & 88 \\
\hline & & Third & 9.0 & 57.0 & 32.2 & 1.7 & 5,000 & 450 & 2,850 & 1,610 & 85 \\
\hline & \multirow{2}{*}{2} & First & 25.2 & 41.2 & 32.5 & 1.0 & 13,250 & 3,339 & 5,459 & 4,306 & 132 \\
\hline & & Third & 6.7 & 57.2 & 35.0 & 11 & 7,125 & 477 & 4,075 & 2,493 & 71 \\
\hline & \multirow{2}{*}{3} & First & 30.0 & 45.0 & 23.0 & 2.0 & 21,000 & 6,300 & 9,450 & 4,830 & 420 \\
\hline & & Third & 7.0 & 65.0 & 27.0 & 1.0 & 10,000 & 700 & 6,500 & 2,700 & 100 \\
\hline \multirow{2}{*}{ 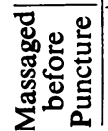 } & \multirow{2}{*}{4} & First & 6.7 & 59.2 & 32.5 & 1.5 & 8,000 & 536 & 4,736 & 2,600 & 120 \\
\hline & & Third & 7.0 & 62.0 & 29.5 & 1.5 & 8,250 & 577 & 5,115 & 2,433 & 123 \\
\hline
\end{tabular}

to the 0.7 mark. The blood was then expelled on to the end of a microscope slide so as to mix the cells thoroughly, and part was drawn up again into the pipette to the 0.5 mark and diluted $1: 20$ with $1 \%$ acetic acid solution. The remainder left on the slide was spread as a film. In this way the same mixture of cells for both total and differential counts was assured. The spreader used was narrower than the slide so that the horizontal edges of the film where the monocytes and polymorphs tend to accumulate could be included in the differential count. A second drop was then expressed and wiped away, and the third drop taken into another "Thoma " white-cell pipette and the same procedure repeated. Four representative counts are shown in Table II. They were taken from four healthy men. The site of puncture was the ear, body posture upright, and the external temperature cool. In the films 400 cells were counted in parallel vertical fields.

\section{Results}

The total count in the first drop is raised, but whether or not the rise constitutes a false leucocytosis depends not only on the degree of concentration of the cells in the capillaries of the ear but upon the level of the true count as shown in the third drop. Thus in Case 1, where the true count, 5,000 per c.mm., is a low normal count, the false count, 8,875 per c.mm., does not amount to a marked leucocytosis. But in Cases 2 and 3, where the true counts are 7,125 and 10,000 per c.mm., there is in the first drop a false leucocytosis of 13,250 and 21,000 per c.mm. respectively.

The absolute counts of all the leucocytes are raised, but the degree of increase is much the greatest in the case of the monocytes. These cells in Case 1 are increased nearly six times, in Case 2 seven times, and in Case 3 nine times, whereas the neutrophil polymorphs and the lymphocytes are in no case doubled. 
In Case 4 a brisk circulation was assured before puncture by massaging the ear for three seconds. The counts are seen to be approximately the same in first and third drops.

Red Cell Count and Haemoglobin Content.-Numerous estimations showed that these were not affected even when there was a concentration of leucocytes in the first drop of blood from the ear. The sluggish stream allows the leucocytes to collect along the capillary walls, but the red cells evidently flow slowly on without becoming packed.

\section{Effect of Alcohol or Ether on the Skin and Rubbing on Blood Count}

Most haematologists advise the use of alcohol or ether, but others consider them to be harmful. If their purpose is to sterilize the skin they may as well be discarded, because all that is necessary to prevent sepsis is to use a sterile pricker. If their purpose is to remove the natural grease from the skin, again they should be discarded, because this grease facilitates the formation of a well-rounded blood drop which is an advantage.

According to Price-Jones (1933), “The auricle should be gently massaged and not rubbed: cleaning with iodine, ether, etc., is not necessary and should be avoided in view of the artificial hyperaemia, the possible leucocytic attraction, and introduction of tissue juice likely to be set up thereby."

Gulland and Goodall (1925) conclude that "elaborate antiseptic precautions are unnecessary, and cleaning with ether should be avoided."

I have tested both alcohol and ether in this respect and do not find that they affect the blood count in any way, but I consider them unnecessary and do not use them.

Hyperaemia is desirable as it promotes a free flow of blood from the puncture. It is most conveniently produced by massaging the part between finger and thumb for three seconds. In the case of the ear this procedure has the additional advantage of dispersing any concentration of leucocytes which may be present. To make assurance doubly sure the first drop or two of blood should be wiped away.

\section{Summary}

The ear in man, owing to atrophy of its muscles, is immobile, hence its capillary circulation is not aided by muscular contraction, and in the absence of external warmth, pressure, bending movements, or a speeding-up of its rate of flow secondary to exercise, its capillary circulation tends to slow down. When this happens the leucocytes start concentrating along the capillary walls.

The various kinds of leucocytes are not concentrated to the same extent: the monocytes cling to the capillary walls far more than other cells. Samples of blood under such conditions show distorted differential percentage and absolute counts, and a raised total leucocyte count which may amount to a false leucocytosis.

The concentration of leucocytes when tapped by puncture is found in the first drop of blood from the ear. It is not found in the third drop, which represents a refill from the arterioles and gives a true picture as found in the general circulation of the leucocytes. 
A high percentage of monocytes in the first but not in the third drop is a sure indication that the first count is due to a fortuitous concentration. Such a concentration can be dispersed by massage, warmth, bending down, or exercise.

External temperature affects the capillary circulation of the ear. A leucocyte concentration occurs in moderately cool and cold weather but not in hot weather, nor is it found in persons working in warm rooms. Body posture affects it. It is not found in recumbent bed-patients, but it is likely to occur among out-patients.

To avoid this error the part of the ear to be pricked should be massaged for three seconds and, as an extra precaution, the third drop taken.

In the case of the finger the capillary circulation is kept brisk by muscular contraction and movement of the part, consequently the leucocyte picture is reliable whichever drop is examined.

\section{REFERENCE3}

Gulland, G. L., and Goodall, A. (1925). The Blood. Green. Edinburgh. P. 1. Lucey, H. C. (1921). Trop. Sect. Proc. R. Soc. Med., 14, 53.

Price-Jones, C. (1933). Blood Pictures. Wright. Bristol. P. 8.

[The author does not take into account the possibility of local endothelial activity, which certainly plays some part in the production of this effect, especially in acrocyanosis associated with bacterial endocarditis.-ED.] 